\title{
TUMOR CARDIACO SECUNDARIO A LINFOMA DE BURKITT EN ADULTO CON VIH
}

\author{
CARDIAC MASS IN PATIENT WITH BURKITT LYMPHOMA IN PATIENT \\ WITH HIV. CARDIAC MASS IN PATIENT WITH HIV
}

'Especialistas de medicina Interna del Hospital de Clinicas de la Universidad nacional de Asuncion

Hospital de Clinicas de la Universidad nacional de Asunción

Correspondencia a:

Víctor Daniel Giménez Ortigoza victorgimenez11@gmail.com Telf. y celular: +595981311203

Palabras Clave: linfoma de burkitt. tomografía. Ensayo de Inmunoadsorción Enzimática

Key Words: burkitt lymphoma. chest tomography. enzymelinked immunosorbent assay.

Procedencia y arbitraje: no comisionado, sometido a arbitraje externo.

Recibido para publicación: 23 de noviembre de 2018 Aceptado para publicación: 21 de diciembre de 2019

Citar como:

Gimenez V, Santacruz I. Masa cardiaca en paciente con $\mathrm{VIH}$ Rev Cient Cienc Med 2019; 22 (2): 58-59

Victor Daniel Gimenez Ortigoza', Iris Santacruz'.

\section{DESARROLLO}

Ce presenta el caso de un varón de 32 años de edad con cuadro de un mes de evolución de disnea de $\checkmark$ esfuerzo que empeora progresivamente hasta presentarse en el reposo, edema de miembros inferiores, astenia y decaimiento general. Se desconoce si es portador de alguna patologia de base y niega algún cuadro similar anterior. Al examén físico, se constató adenomegalias cervicales e inguinales, ruidos pulmonares en campo medio y base, ingurgitación yugular, ruidos cardiacos normales y hepatomegalia. Se realizó inicialmente radiografía de tórax donde se pudo apreciar mediastino ensanchado, con buena respuesta sintomática inicialmente con restricción de líquidos y diuréticos, posterior a análisis rutinario se constata test Elisa positivo para VIH.

Figura 1: Tomografia contrastada de tórax donde se evidencia tumoración intrauricular hipodensa mal delimitada con infiltracion de ventricular (flecha celeste) y de derrame pleural (flecha naranja).

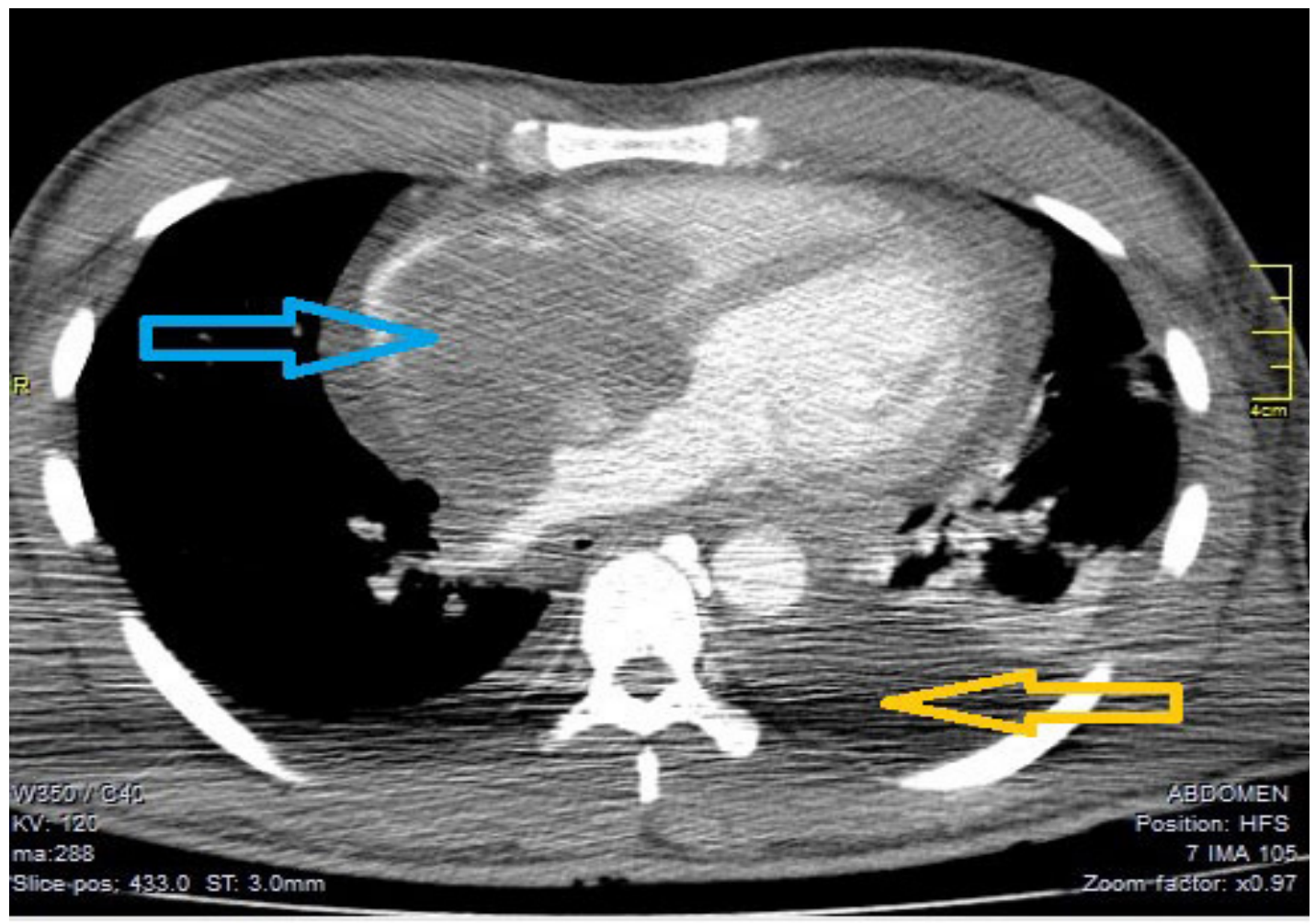

Fuente Propia 
Una vez internado en sala de medicina interna permaneció estable, se realizó una tomografia contrastada (Figura 1) donde se aprecia tumoracion intrauricular hipodensa mal delimitada mide 83 $\mathrm{mm}$ de diametro mayor con infiltracion ventricular (flecha celeste) y derrame pleural con distancia pleura-pleura de $55 \mathrm{~mm}$ (flecha naranja), la carga viral fue de 57000 copias $/ \mathrm{ml}$ y recuento de linfocitos CD4 30 células/ mm3; paciente en estadio SIDA. En interconsulta con departamento de cirugía, se realizó biopsia de ganglio cervical que informó Linfoma de Burkitt mediante citometría de flujo; se inició terapia antiretroviral y quimioterapia de urgencia con citarabina, doxorrobucina y dexametasona por el departemento de hematología.

A pesar de inicio de quimioterapia; el paciente fallece a las 72 horas de ingreso por shock cardiogénico. La presentación de infiltración cardíaca secundaria a linfoma de Burkitt es extremadamente rara en adultos ${ }^{1-5}$, la falta de consulta oportuna y la inmunodeficiencia propiciaron un desenlace fatal.

\section{REFERENCIAS}

1. Tzachanis D, Dewar R, Luptakova K, Chang JD, Joyce RM. Primary cardiac burkitt lymphoma presenting with abdominal pain. Case Rep Hematol [Internet]. 2014 [cited 2018 Dec 25];2014:687598. Available from: http://www.ncbi.nlm.nih.gov/pubmed/25431699

2. Legault S, Couture C, Bourgault C, Bergeron S, Poirier P, Sénéchal M. Primary cardiac Burkitt-like lymphoma of the right atrium. Can J Cardiol [Internet]. 2009 Mar [cited 2018 Dec 25];25(3):163-5. Available from: http:// www.ncbi.nlm.nih.gov/pubmed/19279985

3. Ruiz-Mori E, Ayala-Bustamantea L, Ruiz-Morib H, Burgos-Bustamante J, Pérez-Samitier C, Zaharia-Bassan M. Masa tumoral cardiaca en un paciente con linfoma de Burkitt. Caso clínico. Arch Cardiol México [Internet]. 2017 Apr 1 [cited 2018 Dec 25];87(2):187-9. Available from: https://linkinghub.elsevier.com/retrieve/pii/ S1405994016300702

4. Ramírez JD, Patiño Giraldo S, Arango M. Linfoma primario del corazón: causa poco común de síndrome de falla cardiaca. Rev Colomb Cardiol [Internet]. $2016 \mathrm{Sep}$ 1 [cited 2018 Dec 25];23(5):419.e1-419.e5. Available from: https://www.sciencedirect.com/science/article/ pii/S0120563315002338

5. Chan O, Igwe M, Breburda CS, Amar S. Burkitt Lymphoma Presenting as an Intracardiac Mass: Case Report and Review of Literature. Am J Case Rep [Internet]. 2016 Aug 3 [cited 2018 Dec 25];17:5538. Available from: http://www.ncbi.nlm.nih.gov/ pubmed/27484990 